\title{
Exploratory analyses assessing the impact of early tumour shrinkage and depth of response on survival outcomes in patients with $R A S$ wild-type metastatic colorectal cancer receiving treatment in three randomised panitumumab trials
}

\author{
Julien Taieb ${ }^{1}$ (D) Fernando Rivera ${ }^{2} \cdot$ Salvatore Siena $^{3} \cdot$ Meinolf Karthaus $^{4} \cdot$ \\ Manuel Valladares-Ayerbes ${ }^{5} \cdot$ Javier Gallego $^{6} \cdot$ Michael Geissler $^{7} \cdot$ Reija Koukakis $^{8}$. \\ Gaston Demonty ${ }^{9}$ Marc Peeters ${ }^{10}$
}

Received: 29 August 2017 / Accepted: 13 October 2017 / Published online: 28 October 2017

(c) The Author(s) 2017. This article is an open access publication

\begin{abstract}
Purpose To report exploratory analyses of early tumour shrinkage (ETS) and depth of response (DpR) in patients with $R A S$ wild-type (WT) metastatic colorectal cancer (mCRC), receiving the first-line treatment in three randomised panitumumab trials.

Methods Data from the PRIME (NCT00364013), PEAK (NCT00819780) and PLANET (NCT00885885) studies were included. Median DpR, the proportion of patients achieving ETS $\geq 20 \%$ or $\geq 30 \%$ at week 8 , and the impact of ETS and DpR (including by category) on outcome were analysed. Factors associated with ETS and DpR and the optimal ETS/DpR cut-off values for predicting improved overall survival (OS) were assessed.

Results Overall, 505, 170 and 53 patients had RAS WT mCRC in PRIME, PEAK and PLANET, respectively. Patients receiving panitumumab had higher ETS rates ( $\geq 30 \%$ : PRIME $59 \%$ vs. $38 \%$; PEAK $64 \%$ vs. $45 \%$ ) and
\end{abstract}

Electronic supplementary material The online version of this article (doi:10.1007/s00432-017-2534-z) contains supplementary material, which is available to authorized users.

Julien Taieb

julien.taieb@egp.aphp.fr; jtaieb75@gmail.com

1 Department of Hepatogastroenterology and GI Oncology, Georges Pompidou European Hospital and Sorbonne Paris Cité / Université Paris Descartes, 20 rue Leblanc, 75015 Paris, France

2 Hospital Universitario Marqués de Valdecilla, Santander, Spain

3 Grande Ospedale Metropolitano Niguarda and Dipartimento di Oncologia e Emato-Oncologia, Niguarda Cancer Center, Università degli Studi di Milano, Milan, Italy

4 Städtisches Klinikum München, Klinikum Neuperlach, Munich, Germany greater DpR (PRIME: $54 \%$ vs. 46\%; PEAK: $65 \%$ vs. $46 \%$ ) than those receiving treatment without panitumumab. In multiple regression analyses, panitumumab treatment, liver-only metastases and WT $B R A F$ status were consistently associated with improved ETS and DpR outcomes. Irrespective of treatment, ETS and DpR were associated with improved progression-free survival, overall survival and resection rates; most resections occurred in patients in the two highest DpR categories. In PRIME and PEAK, respectively, the optimal cut-offs for predicting improved OS were 32 and $34 \%$ for ETS, and 59 and $70 \%$ for DpR.

Conclusions These exploratory analyses suggest that panitumumab is associated ETS and DpR benefits in patients with RAS WT mCRC and that achieving these endpoints during first-line treatment is linked with favourable outcomes.

Keywords Depth of response - Early tumour shrinkage · Metastatic colorectal cancer · Panitumumab - Survival

Virgen del Rocio Hospital, Seville, Spain

6 Hospital General Universitario de Elche, Elche, Spain

7 Klinikum Esslingen, Esslingen, Germany

Biostatistics, Amgen Ltd, Uxbridge, UK

9 Amgen (Europe) GmbH, Medical Development, Zug, Switzerland

10 Antwerp University Hospital, Antwerp, Belgium 


\section{Introduction}

Tumour response, as defined by Response Evaluation Criteria In Solid Tumours (RECIST), is a common endpoint in clinical trials, and requires that tumour shrinkage of $\geq 30 \%$ is confirmed at consecutive visits (Therasse et al. 2000; Eisenhauer et al. 2009). However, RECIST does not consider timing, depth or duration of response. Achieving early and sustained tumour shrinkage is an important treatment goal in patients with metastatic colorectal cancer (mCRC) as it may increase the chance of surgical resection and provide relief of tumour-related symptoms (Folprecht et al. 2010; Douillard et al. 2015). Two other shrinkage-related endpoints that provide information over and above that provided by RECIST have also started to be utilised in mCRC trials. Early tumour shrinkage (ETS of $\geq 20 \%$ or $\geq 30 \%$ assessed after 6 or 8 weeks of treatment) can provide an early indication of sensitivity to treatment (Piessevaux et al. 2013; Giessen et al. 2013; Modest et al. 2013; Douillard et al. 2015; Heinemann et al. 2015; Cremolini et al. 2015), whereas depth of response (DpR) assesses the maximum tumour shrinkage achieved by a patient during treatment (Heinemann et al. 2015).

In first-line trials comparing epidermal growth factor receptor inhibitors (EGFRIs) plus chemotherapy vs. bevacizumab plus chemotherapy in patients with mCRC, the EGFRIs resulted in higher rates of ETS and were also associated with greater median DpR (Stintzing et al. 2016; Rivera et al. 2017). Furthermore, exploratory analyses of first-line trial data demonstrated that both ETS and DpR were associated with improved overall survival (OS) (Mansmann et al. 2013; Cremolini et al. 2015; Douillard et al. 2015; Heinemann et al. 2015; Stintzing et al. 2016; Rivera et al. 2017). Here, we aim to consolidate the available data on the effects of panitumumab on ETS and DpR in first-line RAS wildtype (WT) mCRC, some of which have only been published in congress abstracts to date (Abad et al. 2014; Abad et al. 2015; Rivera et al. 2016; Siena et al. 2016). We further build on these data by reporting new exploratory analyses of the optimal ETS and DpR cut-offs to predict improved OS, multiple regression analyses of factors associated with ETS and DpR, the impact of DpR by category on outcome in PEAK, and the impact of ETS and DpR on response and resection outcomes (where available).

\section{Methods}

\section{Included studies and patients}

Three first-line panitumumab mCRC studies were included in these analyses. PRIME (NCT00364013) was a phase III trial comparing panitumumab plus FOLFOX4 vs. FOLFOX4 alone (Douillard et al. 2010, 2015). PEAK (NCT00819780) was a phase II study comparing panitumumab plus modified (m)FOLFOX6 vs. bevacizumab plus mFOLFOX6 (Schwartzberg et al. 2014; Rivera et al. 2017). PLANET (NCT00885885) was a phase II study comparing first-line panitumumab plus FOLFOX4 vs. panitumumab plus FOLFIRI (Abad et al. 2014, 2015).

The present analyses included data from patients in these studies who had RAS WT mCRC (i.e. those whose tumours contained no mutations in KRAS and NRAS exons 2 [codons 12 and 13], 3 [codons 59 and 61] and 4 [codons 117 and 146]). All analyses and $p$ values are descriptive.

\section{Early tumour shrinkage analyses}

Tumour shrinkage measurements were based on the sum of the longest diameters $(\mathrm{mm})$ of measurable target lesions. $R A S$ WT data were analysed to determine the proportion of patients achieving ETS $\geq 20 \%$ or $\geq 30 \%$ at week 8 (compared with baseline) in each study and the impact of ETS $\geq 20 \%$ and $\geq 30 \%$ (overall and by treatment) on progression-free survival (PFS) and OS were also assessed. Multiple regression analyses were performed to determine baseline factors associated with ETS in the PRIME and PEAK studies. ETS was included as a continuous variable (i.e. each patient's percentage shrinkage at week 8) and a stepwise model building procedure was used, with a $10 \%$ significance level for a covariate to enter or remain in the model. The effect of ETS on RECIST response and the proportions of patients undergoing resection who experienced ETS were also evaluated, where possible.

A study-level meta-analysis was conducted to estimate the effect of ETS $\geq 20 \%$ vs. $<20 \%$ and ETS $\geq 30 \%$ vs. $<30 \%$ on PFS, OS and resection (complete [R0] and/ or partial [R1] resection) rates in patients with $R A S$ WT $\mathrm{mCRC}$ receiving first-line treatment (overall) in these three studies. Meta-analysis techniques, including fixed-effect modelling (unconditional maximum likelihood method) and random-effect modelling (DerSimonian and Laird modelling methods) (DerSimonian and Laird 1986), were used to pool study-level trial data using the inverse-variance of each study as the weight. An exploratory analysis to estimate the optimal ETS cut-off value for prediction of improved OS in the PRIME and PEAK studies was performed according to a previously published method (Contal and O'Quigley 1999).

\section{Depth of response analyses}

DpR was calculated as the maximum percentage change from baseline to nadir in patients who had tumour shrinkage and median DpR was calculated by treatment in the three studies. DpR had a positive value for tumour reduction, negative for tumour growth, and zero for no change. Patients 
who had measurable disease at baseline and calculable $\mathrm{DpR}$ post-baseline, were included in these analyses. Multiple regression analyses were performed to determine baseline factors associated with DpR in the PRIME and PEAK studies. DpR was included as a continuous variable (i.e. each patient's maximum percentage shrinkage) and a stepwise model building procedure was used, with a $10 \%$ significance level for a covariate to enter or remain in the model.

DpR was also analysed by category in the PRIME and PEAK studies (data not available for PLANET). Here, patients with tumour growth were categorised as having $\mathrm{DpR}<0 \%$, with the remainder subdivided into four additional DpR categories based on the extent of observed shrinkage. These categories included the RECIST cut-off for a partial response (30\%) and three further approximately equally sized groups based on patient quartiles (PRIME DpR cut-offs: 0-30\%, 31-52\%, 53-70\%, 71-100\%; PEAK DpR cut-offs: $0-30 \%, 31-53 \%, 54-82 \%$ and $83-100 \%$ ). The overall impact of DpR (irrespective of treatment) on PFS and OS outcomes and RECIST response, duration of response (DoR) and resection rates, was evaluated, with DpR evaluated both as a continuous and ordinal variable, in simple and multiple Cox regression models. The multiple Cox regression model also included terms for treatment and stratification factors (baseline Eastern Cooperative Oncology Group [ECOG] performance status and region). Exploratory analyses comparing PFS and OS in patients with DpR of $\geq 30 \%$ vs. DpR of $<30 \%$ (i.e. utilising the RECIST cutoff for response) and DpR of $\geq 20 \%$ vs. DpR of $<20 \%$, were also performed. An exploratory analysis to estimate the optimal DpR cut-off value for prediction of improved OS in the PRIME and PEAK studies was performed according to a previously published method (Contal and O'Quigley 1999).

\section{Results}

\section{Patients}

Overall, 505, 170 and 53 patients had RAS WT mCRC in the PRIME, PEAK and PLANET studies, respectively (Table 1). Baseline demographics were generally similar between studies except that more patients were male in PLANET (77\%) than PRIME (65\%) or PEAK (67\%). Furthermore, all patients in PLANET had liver-limited metastatic disease (in line with the study inclusion criteria), compared with 18 and $26 \%$ in the PRIME and PEAK studies, respectively.

In PRIME and PEAK, baseline demographics and disease characteristics were generally similar across DpR categories, although patients with $\mathrm{DpR}<0 \%$ more commonly had BRAF mutant tumours (Supplementary Table S1). In PRIME, DpR $<0 \%$ more commonly occurred in patients

Table 1 Baseline demographics and disease characteristics for patients in the PEAK, PLANET and PRIME studies with available data (RAS wild-type population)

\begin{tabular}{|c|c|c|c|c|c|c|}
\hline & \multicolumn{2}{|c|}{$\operatorname{PEAK}(n=170)^{\mathrm{a}}$} & \multicolumn{2}{|c|}{$\operatorname{PLANET}(n=53)^{\mathrm{b}}$} & \multicolumn{2}{|c|}{$\operatorname{PRIME}(n=505)^{\mathrm{c}}$} \\
\hline & $\begin{array}{l}\text { Pmab + FX6 } \\
(n=88)\end{array}$ & $\begin{array}{l}\text { Beva + FX6 } \\
(n=82)\end{array}$ & $\begin{array}{l}\text { Pmab + FX4 } \\
(n=27)\end{array}$ & $\begin{array}{l}\text { Pmab + FI } \\
(n=26)\end{array}$ & $\begin{array}{l}\text { Pmab + FX4 } \\
(n=253)\end{array}$ & $\mathrm{FX} 4(n=252)$ \\
\hline Male sex, $n(\%)$ & $58(66)$ & $56(68)$ & $23(85)$ & $18(69)$ & $170(67)$ & $158(63)$ \\
\hline $\begin{array}{l}\text { Age-median, } \\
\text { years (range) }\end{array}$ & $62(23-82)$ & $60(39-82)$ & $66(32-79)$ & $60(37-78)$ & $61(27-81)$ & $61(24-82)$ \\
\hline $\begin{array}{l}\text { ECOG PS } 0 / 1, n \\
(\%)\end{array}$ & $88(100)$ & $81(99)^{\mathrm{d}}$ & NA & NA & $238(94)$ & $235(93)$ \\
\hline \multicolumn{7}{|c|}{ Primary cancer diagnosis, $n(\%)$} \\
\hline Colon & $64(73)$ & $57(70)$ & NA & NA & $165(65)$ & $164(65)$ \\
\hline Rectal & $24(27)$ & $25(30)$ & NA & NA & $88(35)$ & $88(35)$ \\
\hline \multicolumn{7}{|c|}{ Side of disease, $n(\%)$} \\
\hline Left & $53(60)$ & $54(66)$ & NA & NA & $169(67)$ & $159(63)$ \\
\hline Right & $22(25)$ & $14(17)$ & NA & NA & $39(15)$ & 49 (19) \\
\hline Unknown & $13(15)$ & $14(17)$ & NA & NA & $45(18)$ & $44(17)$ \\
\hline \multicolumn{7}{|c|}{ Sites of metastases, $n(\%)$} \\
\hline Liver only & $23(26)$ & $22(27)$ & $27(100)$ & $26(100)$ & $48(19)$ & $41(16)$ \\
\hline Liver + other & $43(49)$ & $34(41)$ & $0(0)$ & $0(0)$ & $169(67)$ & $172(68)$ \\
\hline Other only & $22(25)$ & $26(32)$ & $0(0)$ & $0(0)$ & $36(14)$ & $39(15)$ \\
\hline
\end{tabular}

ECOG PS Eastern Cooperative Oncology Group performance status, FI FOLFIRI, FX4 FOLFOX4, FX6 mFOLFOX6, NA not available ${ }^{\mathrm{a}} n=154 ;{ }^{\mathrm{b}} n=47 ;{ }^{\mathrm{c}} n=440$ included in the early tumour shrinkage analyses, respectively, from these studies

${ }^{\mathrm{d}}$ ECOG PS was missing/unknown for 1 patient in this group 
receiving FOLFOX4 alone (Supplementary Table S1A), while in PEAK the three patients with $\mathrm{DpR}<0 \%$ all received panitumumab plus mFOLFOX6 (Supplementary Table S1B). Overall, in these two studies, the three lowest $\mathrm{DpR}$ categories generally included proportionally more patients with right-sided tumours than the two highest $\mathrm{DpR}$ categories.

\section{Early tumour shrinkage: individual study data}

\section{PRIME}

Overall, 440 patients were included in the ETS analyses; $283(64 \%)$ achieved ETS $\geq 20 \%$ and $213(48 \%)$ achieved ETS $\geq 30 \%$ (Douillard et al. 2015). Of the patients with ETS $\geq 20 \%$ and ETS $\geq 30 \%$, respectively, 225 (80\%) and $185(87 \%)$ were subsequently confirmed as achieving a RECIST response (partial or complete), with the remainder having a best overall response of stable (SD) or progressive disease (PD).

Sixty-one patients underwent a resection (R0 and/or R1) and also had ETS data. Of these, 51 (84\%) experienced ETS $\geq 20 \%$ and $42(69 \%)$ had ETS $\geq 30 \%$. Likewise, 44 patients had R0 resections and ETS data. Of these, 38 (86\%) experienced ETS $\geq 20 \%$ and $33(75 \%)$ had ETS $\geq 30 \%$.

More patients receiving panitumumab plus FOLFOX4 vs. FOLFOX 4 alone had ETS $\geq 20 \%$ ( $72 \%$ vs. $57 \%$, odds ratio [OR]: 1.99 [95\% CI 1.34, 2.96]; $p<0.001)$ or $\geq 30 \%(59 \%$ vs. 38\%, OR 2.43 [95\% CI 1.66, 3.56]; $p<0.001$ ) (Douillard et al. 2015). Factors associated with improved ETS in the final multiple regression model were panitumumab treatment (vs. FOLFOX4 alone), liver-only metastases (vs. liver + other or other only metastases) and WT BRAF status (vs. mutant) (Table 2a).

Amongst patients achieving ETS $\geq 30 \%$, those receiving panitumumab plus FOLFOX4 had longer median PFS (14.9 vs. 10.9 months, hazard ratio [HR]: 0.70 [95\% confidence interval $\{\mathrm{CI}\}$ 0.51,0.94]; $p=0.019$ ) compared with those receiving FOLFOX4 alone; median OS was 34.5 vs. 30.7 months, respectively (HR 0.85 [95\% CI $0.62,17] ; p=0.31$ ) (Douillard et al. 2015). PFS (9.3 vs. 7.0 months, HR 0.78 [95\% CI 0.59, 1.03]; $p=0.790$ ) and OS (18.2 vs. 16.0 months, HR 0.80 [95\% CI $0.60,1.06$ ]; $p=0.1249$ ) outcomes were similar between treatments for those patients with ETS $<30 \%$. Irrespective of treatment received, patients achieving ETS $\geq 20 \%$ (HR $0.60[95 \%$ CI $0.49,0.73]$ ) or $\geq 30 \%$ (HR 0.55 [95\% CI $0.45,0.68]$ ) had significantly longer PFS. Similar results were seen for the impact of ETS $\geq 20 \%$ (HR 0.47 [95\% CI 0.38, 0.58]) or $\geq 30 \%$ (HR 0.48 [95\% CI 0.38, 0.59]) on OS. In PRIME, the optimal ETS cut-off for prediction of improved OS outcomes was $32 \%(p<0.0001)$.
PEAK

Overall, 154 patients were included in the ETS analyses; 106 patients $(69 \%)$ achieved ETS $\geq 20 \%$ and $84(55 \%)$ achieved ETS $\geq 30 \%$ (Rivera et al. 2017). Of the patients with ETS $\geq 20 \%$ and ETS $\geq 30 \%$, respectively, 93 (88\%) and 76 (90\%) were subsequently confirmed as achieving a RECIST response (partial or complete), with the remainder having a best overall response of SD or PD. Twenty-three patients had a resection (R0 and/or R1) and ETS data, of these, 18 (78\%) had ETS $\geq 20 \%$ and $15(65 \%)$ had ETS $\geq 30 \%$. Sixteen patients had R0 resections and ETS data, of these, 13 (81\%) had ETS $\geq 20 \%$ and $12(75 \%)$ had ETS $\geq 30 \%$.

Compared with the bevacizumab plus mFOLFOX6 arm, more patients receiving panitumumab plus mFOLFOX6 had ETS $\geq 30 \%$ (64\% vs. $45 \%$, OR 1.99 [95\% CI 0.99, 4.10]; $p=0.052$ ) (Rivera et al. 2017). Similar observations were noted regarding the ETS $\geq 20 \%$ cut-off ( $75 \%$ vs. $62 \%$, OR 1.67 [95\% CI 0.78, 3.58]; $p=0.21$ ). Factors associated with improved ETS in the final multiple regression model were panitumumab treatment (vs. bevacizumab), liver-only metastases (vs. liver + other or other only metastases) and WT $B R A F$ status (vs. mutant) (Table $2 b$ ).

For those achieving ETS $\geq 20 \%$, median PFS was 13.1 vs. 11.3 months in the panitumumab plus mFOLFOX6 vs. bevacizumab plus mFOLFOX6 group (HR 0.70 [95\% CI 0.45, 1.08]; $p=0.11$ ) (Rivera et al. 2017). Among those achieving ETS $\geq 30 \%$, median PFS was 13.0 vs. 11.1 months, respectively (HR 0.74 [95\% CI $0.45,1.22] ; p=0.24$ ). When treatment arms were combined, achievement of ETS $\geq 20 \%$ was associated with longer PFS (HR 0.55 [95\% CI 0.37, 0.81]; $p=0.0029$ ). Similar results were seen when combined data were analysed using the $\geq 30 \%$ ETS cut-off (HR $0.60[95 \%$ CI 0.42, 0.87]; $p=0.0065$ ). Likewise, irrespective of treatment received, patients achieving ETS $\geq 20 \%$ (HR 0.39 [95\% CI $0.26,0.59$ ] $; p<0.0001$ ) or $\geq 30 \%$ (HR 0.44 [95\% CI 0.30, 0.65]; $p<0.0001$ ) had longer OS. In PEAK, the optimal ETS cut-off for prediction of improved OS was $34 \%$ $(p=0.0006)$.

\section{PLANET}

Overall, 47 patients were included in the ETS analyses with 37 patients (79\%) achieving ETS $\geq 20 \%$ (76 and $81 \%$ in the panitumumab + FOLFOX4 and panitumumab + FOLFIRI arms, respectively) (Abad et al. 2015). Thirty-one patients (66\%) experienced ETS $\geq 30 \%$ (62 and $71 \%$ in the panitumumab + FOLFOX4 and panitumumab + FOLFIRI arms, respectively). As patient-level data were not available from PLANET, analyses of factors associated with ETS were not possible.

Overall resection rates (R0 and/or R1) were higher in patients achieving ETS $\geq 30 \%$ vs. $<30 \%$ (65\% vs. $31 \%$; 
Table 2 Baseline factors associated with early tumour shrinkage and depth of response (a, PRIME; b, PEAK studies) (RAS wild-type population; multiple regression analyses including early tumour shrinkage and depth of response as continuous variables)

\begin{tabular}{|c|c|}
\hline (a) Factors associated with early tumour shrinkage & Estimate $(95 \% \mathrm{CI})$ \\
\hline \multicolumn{2}{|l|}{ Treatment } \\
\hline Panitumumab + FOLFOX4: FOLFOX4 & $9.62(5.7,13.5)$ \\
\hline \multicolumn{2}{|l|}{ Sites of metastases } \\
\hline Liver + other: liver only & $-5.79(-11.0,-0.60)$ \\
\hline Other only: liver only & $-12.86(-19.8,-5.9)$ \\
\hline \multicolumn{2}{|l|}{$B R A F$ status } \\
\hline Mutant: wild-type & $-10.80(-17.1,4.5)$ \\
\hline Factors associated with depth of response & Estimate $(95 \% \mathrm{CI})$ \\
\hline \multicolumn{2}{|l|}{ Treatment } \\
\hline Panitumumab + FOLFOX4: FOLFOX4 & $8.16(2.1,14.2)$ \\
\hline \multicolumn{2}{|l|}{ Sites of metastases } \\
\hline Liver + other: liver only & $-18.26(-26.2,-10.3)$ \\
\hline Other only: liver only & $-29.13(-40.0,-18.2)$ \\
\hline \multicolumn{2}{|l|}{$B R A F$ status } \\
\hline Mutant: wild-type & $-30.81(-40.6,-21.0)$ \\
\hline \multicolumn{2}{|l|}{ Eastern Cooperative Oncology Group performance status } \\
\hline 2: 0 or 1 & $-14.39(-27.9,-0.9)$ \\
\hline (b) Factors associated with early tumour shrinkage & Estimate $(95 \% \mathrm{CI})$ \\
\hline \multicolumn{2}{|l|}{ Treatment } \\
\hline Panitumumab + mFOLFOX6: bevacizumab + mFOLFOX6 & $6.73(1.4,12.1)$ \\
\hline \multicolumn{2}{|l|}{ Sites of metastases } \\
\hline Liver + other: liver only & $0.35(-6.1,6.8)$ \\
\hline Other only: liver only & $-6.5(-13.6,0.6)$ \\
\hline \multicolumn{2}{|l|}{$B R A F$ status } \\
\hline Mutant: wild-type & $-10.5(-20.9,-0.2)$ \\
\hline Factors associated with depth of response & Estimate $(95 \% \mathrm{CI})$ \\
\hline \multicolumn{2}{|l|}{ Treatment } \\
\hline Panitumumab + mFOLFOX6: bevacizumab + mFOLFOX6 & $12.30(2.9,21.7)$ \\
\hline \multicolumn{2}{|l|}{ Sites of metastases } \\
\hline Liver + other: liver only & $-9.58(-20.9,1.7)$ \\
\hline Other only: liver only & $-19.55(-32.0,7.1)$ \\
\hline \multicolumn{2}{|l|}{$B R A F$ status } \\
\hline Mutant: wild-type & $-14.78(-31.9,2.3)$ \\
\hline \multicolumn{2}{|l|}{ Age } \\
\hline Continuous variable & $-0.47(-1.0,0.1)$ \\
\hline
\end{tabular}

A stepwise model building procedure was used with a $10 \%$ significance level for a covariate to enter or remain in the model. Positive estimates indicate increased depth of response for the second level of the covariate relative to the first level of the covariate (level 1: level 0). Negative estimates indicate decreased depth of response for the second level of covariate relative to the first level of the covariate (level 1: level 0)

CI confidence interval

$p=0.030$ ); similar results were seen in those achieving ETS $\geq 20 \%$ vs. $<20 \%$ (59\% vs. $30 \% ; p=0.19)$ (Abad et al. 2015). No data on R0 resections are currently available from PLANET.

Among those achieving ETS $\geq 20 \%$ and ETS $\geq 30 \%$, PFS outcomes were similar between treatment arms (median PFS 14.2 vs. 14.9 months and 16.4 vs. 18.6 months in the panitumumab + FOLFOX 4 and panitumumab + FOLFIRI arms, respectively) (Abad et al. 2015). When treatment arms were combined, achievement of ETS $\geq 20 \%$ was associated with longer PFS (HR 0.32 [95\% CI 0.14, 0.70]; $p=0.005$ ) and OS (HR 0.31 [95\% CI 0.11, 0.83]; $p=0.020$ ). Similarly, achievement of ETS $\geq 30 \%$ was associated with longer PFS (HR 0.41 [95\% CI 0.21, 0.79]; $p=0.008)$ and OS (HR 0.28 [95\% CI $0.10,0.77] ; p=0.014$ ) outcomes. 


\section{Meta-analysis assessing the impact of early tumour shrinkage on outcome}

Overall, 641 patients with RAS WT mCRC were evaluable for OS and ETS in these studies and so were included in the ETS meta-analyses (Rivera et al. 2016). This comprised 440, 154 and 47 patients from the PRIME, PEAK and PLANET studies, respectively. A meta-analysis of overall resection (R0 and/or R1) data favoured ETS $\geq 20 \%$ vs. ETS < 20\% (OR 0.36 [95\% CI 0.21, 0.63]; Fig. 1a) and ETS $\geq 30 \%$ vs. ETS < 30\% (OR 0.40 [95\% CI 0.25, 0.63]; Fig. 1b). Similarly, a meta-analysis of R0 resection data from PRIME and PEAK (data unavailable for PLANET) favoured ETS $\geq 20 \%$ vs. ETS $<20 \%$ (OR 0.31 $[95 \%$ CI $0.15,0.65]$ ) and ETS $\geq 30 \%$ vs. ETS $<30 \%$ (OR 0.30 [95\% CI 0.16, 0.55]). A meta-analysis of R0 resections performed in patients with liver-limited metastatic disease from these studies was also suggestive of a benefit for ETS $\geq 20 \%$ vs. $<20 \%$ (OR 0.87 [95\% CI $0.31,2.47$ ]) and ETS $\geq 30 \%$ vs. $<30 \%$ (OR 0.51 [95\% CI $0.21,1.25]$ ).
Impact of early tumour shrinkage on progression-free and overall survival

Weighted meta-analysis results for PFS favoured ETS $\geq 20 \%$ vs. ETS < 20\% (HR 0.57 [95\% CI 0.48, 0.68]; Fig. 2a) (Rivera et al. 2016). Results were similar for ETS $\geq 30 \%$ vs. ETS < 30\% (HR 0.55 [95\% CI 0.46, 0.65]; Fig. 2b). Weighted meta-analysis results for OS also favoured ETS $\geq 20 \%$ vs. ETS < 20\% (HR 0.45 [95\% CI 0.37, 0.54]; Fig. 3a) and results were similar for the ETS $\geq 30 \%$ vs. ETS $<30 \%$ cut-offs (HR 0.46 [95\% CI 0.38, 0.55]; Fig. 3b).

\section{Depth of response}

Due to the nature of the data, a meta-analysis of DpR data was not possible; therefore, DpR results are presented by study.

\section{PRIME}

Overall, 460 patients with $R A S$ WT mCRC were included in the analysis; median DpR was higher in patients receiving
Fig. 1 Meta-analysis assessing impact of early tumour shrinkage $(\mathbf{a} \geq 20 \% ; \mathbf{b} \geq 30 \%)$ on resection rates ( $R A S$ wildtype population) $C I$ confidence interval, ETS early tumour shrinkage, $O R$ odds ratio (for ETS $\geq 20 \% / \mathrm{ETS}<20 \%$ and ETS $\geq 30 \% / \mathrm{ETS}<30 \%$, respectively), $S E$ standard error weight is relative weight (\%) from the fixed-effect models
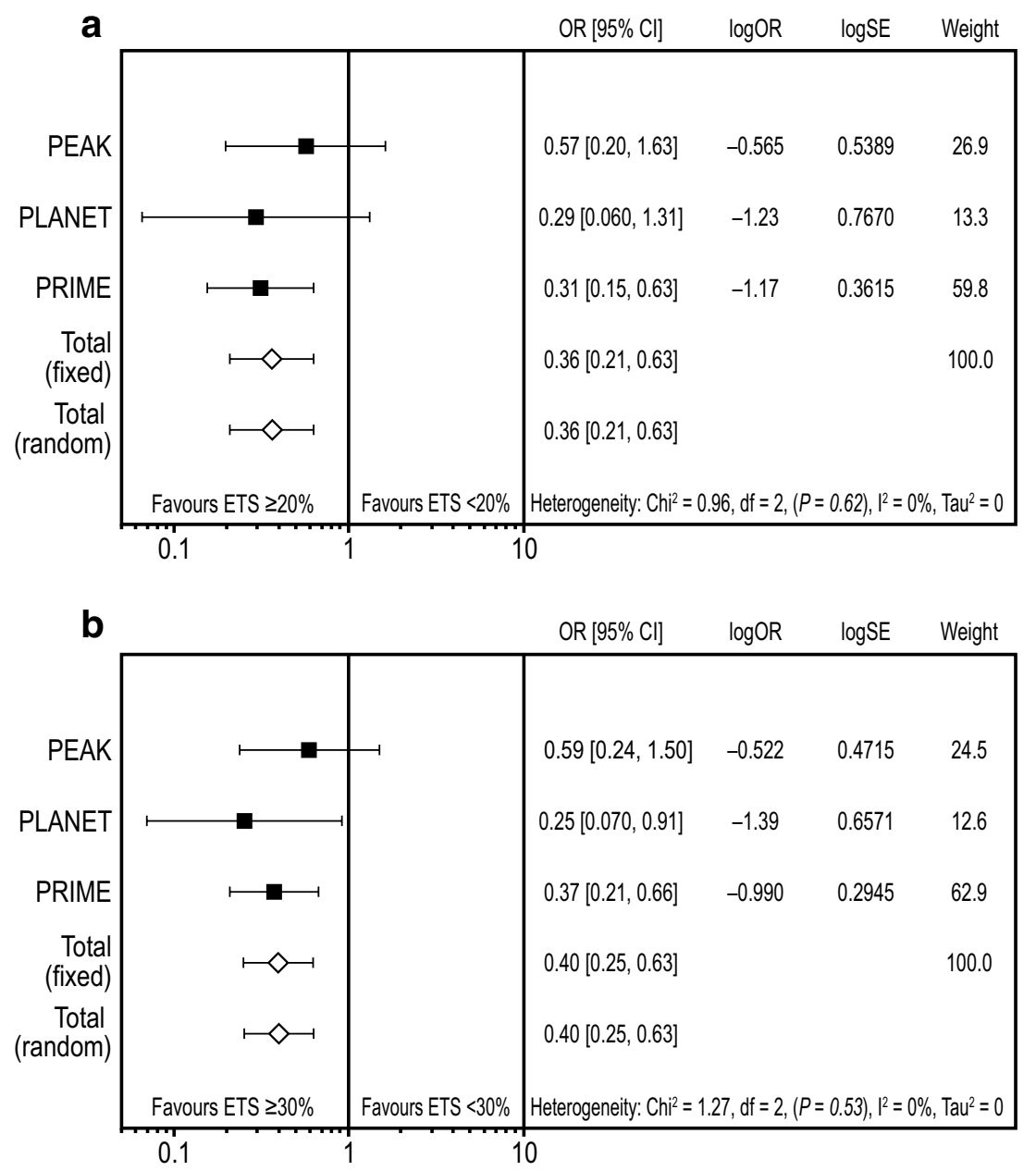
Fig. 2 Meta-analysis assessing impact of early tumour shrinkage (a $\geq 20 \%$; b 30\%) on progression-free survival ( $R A S$ wild-type population) $C I$ confidence interval, ETS early tumour shrinkage, $H R$ hazard ratio, $S E$ standard error weight is relative weight (\%) from the fixed-effect models
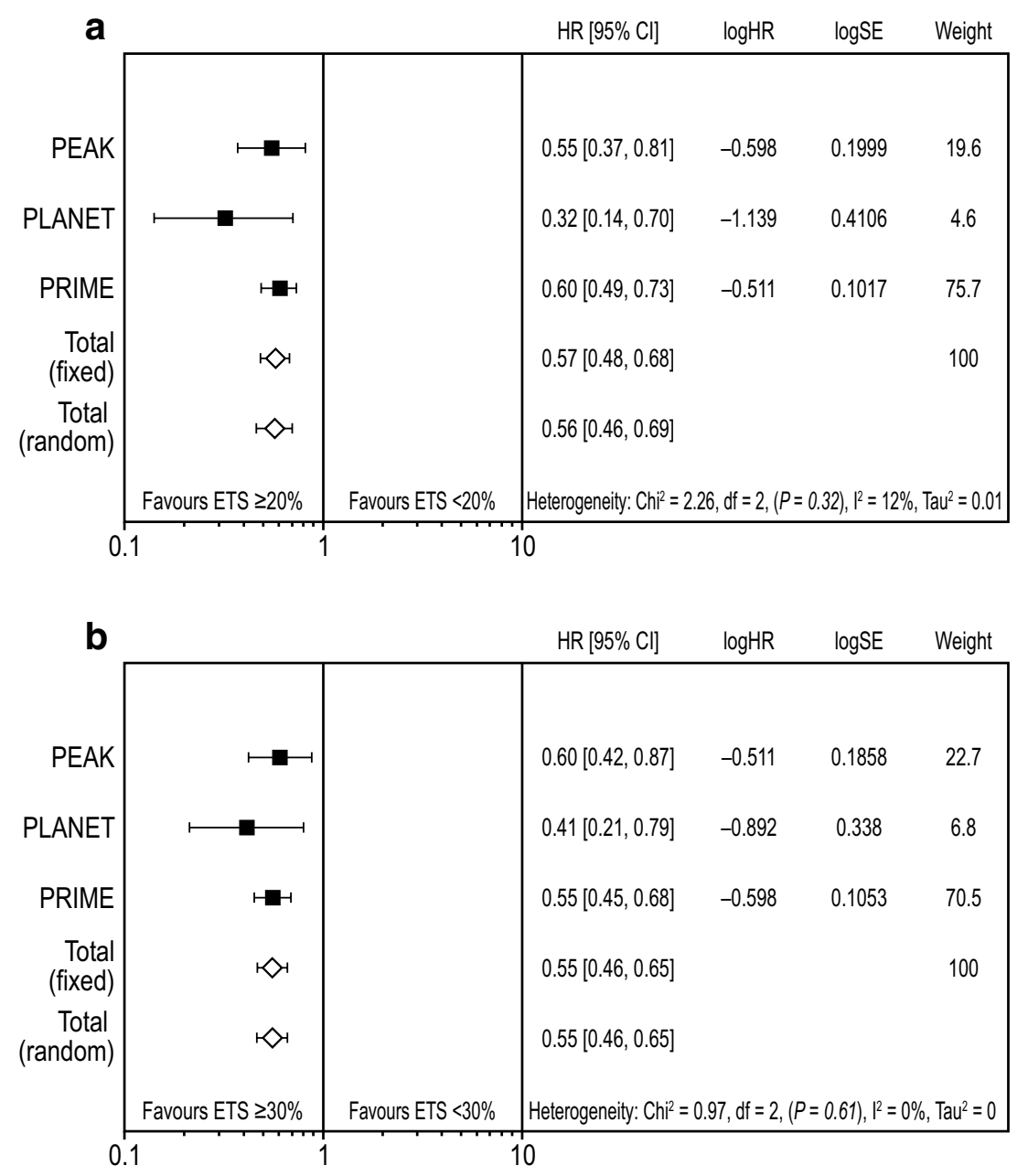

panitumumab plus FOLFOX4 vs. FOLFOX4 alone (54\% vs. $46 \% ; p=0.0149$ ) (Douillard et al. 2015). The distribution of DpR in the PRIME study (by treatment) is shown in Fig. 4a. Factors associated with improved DpR in the final multiple regression model were panitumumab treatment (vs. FOLFOX4 alone), liver-only metastatic disease (vs. liver + other or other only), WT BRAF status (vs. mutant) and an ECOG performance status of 0 or 1 (vs. 2) (Table 2a).

Irrespective of treatment received, patients with deeper responses had longer PFS and OS (Table 3a, Fig. 5 and Supplementary Fig. S1A); median PFS and OS were shortest in those patients experiencing tumour growth (Group 1: DpR < 0\%) (Siena et al. 2016). Median OS exceeded 48 months in those patients experiencing a DpR of 71-100\%. DpR was also associated with PFS $(p<0.0001)$ and OS $(p<0.0001)$ when analysed as a continuous variable in a multiple Cox regression model (Table 2a). In PRIME, the optimal DpR cut-off for prediction of improved OS was $59 \%$.

In an analysis using the RECIST cut-off for response, patients achieving a DpR of $\geq 30 \%$ had longer PFS (median 11.9 vs. 3.8 months, HR 3.25 [95\% CI 2.62,
4.04]; $p<0.0001)$ and OS (median 30.3 vs. 9.4 months, HR 3.24 [95\% CI 2.59, 4.05]; $p<0.0001$ ) compared with those achieving a DpR of $<30 \%$. Similarly, patients achieving a DpR of $\geq 20 \%$ had longer PFS (median 11.5 vs. 3.7 months, HR 5.89 [95\% CI 4.55, 7.62]; $p<0.0001$ ) and OS (median 28.7 vs. 8.9 months, HR 3.40 [95\% CI 2.67, 4.34]; $p<0.0001)$ compared with those achieving a DpR of $<20 \%$. The greater the DpR, the longer the median DoR and the higher the overall and $\mathrm{R} 0$ resection rates; the proportion of patients experiencing a RECIST response was also greatest in the two highest DpR categories (Table 3a).

\section{PEAK}

Overall, 158 patients were included in the $\mathrm{DpR}$ analysis; median DpR was greater in the panitumumab plus mFOLFOX6 vs. bevacizumab plus mFOLFOX6 group (65\% vs. $46 \% ; p=0.0018$ ) (Rivera et al. 2017). The distribution of DpR in the PEAK study (by treatment) is shown in Fig. 4b. Factors associated with improved DpR in the final multiple regression model were panitumumab treatment (vs. 
Fig. 3 Meta-analysis assessing impact of early tumour shrinkage $(\mathbf{a} \geq 20 \% ; \mathbf{b} \geq 30 \%)$ on overall survival ( $R A S$ wildtype population) $C I$ confidence interval, ETS early tumour shrinkage, $H R$ hazard ratio, $S E$ standard error weight is relative weight (\%) from the fixed-effect models
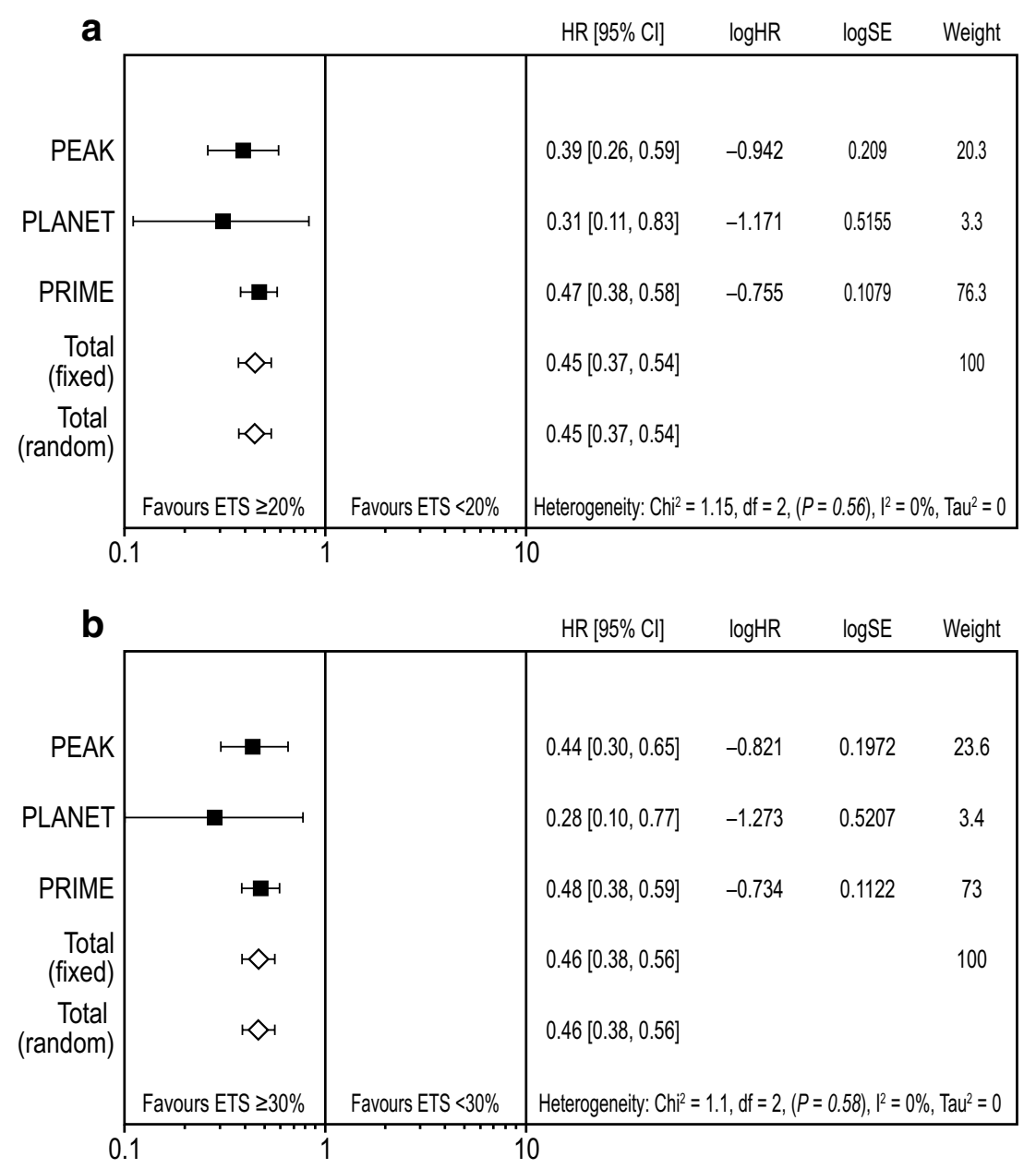

bevacizumab), liver-only metastatic disease (vs. liver + other or other only metastases), WT BRAF status (vs. mutant) and age (decreased vs. increased, continuous variable) (Table 2b).

Patients with deeper responses had longer PFS and OS, irrespective of treatment (Table 3b, Fig. 6 and Supplementary Fig. S1B); median PFS and OS were shortest in those patients experiencing tumour growth (Group 1: DpR $<0 \%$ ). Notably, median OS exceeded 60 months in patients experiencing the greatest DpR (Group 5: DpR of 83-100\%). When analysed as a continuous variable in a multiple Cox regression model, DpR was also associated with PFS ( $p<0.0001)$ and OS ( $p<0.0001)$ (Table 3b). In PEAK, the optimal DpR cut-off for predicting improved OS was $70 \%$.

Patients achieving a DpR of $\geq 30 \%$ had longer PFS (median 13.0 vs. 7.4 months, HR 2.80 [95\% CI 1.86, 4.23]; $p<0.0001$ ) and OS (median 37.4 vs. 17.3 months, HR 3.08 [95\% CI 2.01, 4.71]; $p<0.0001$ ) compared with those achieving a DpR of $<30 \%$. Similarly, patients achieving a DpR of $\geq 20 \%$ had longer PFS (median 12.9 vs. 7.3 months, HR 2.88 [95\% CI 1.77, 4.69]; $p<0.0001$ ) and OS (median 34.4 vs. 21.0 months, HR 2.49 [95\% CI $1.51,4.11] ; p<0.0003$ ) compared with those achieving a $\mathrm{DpR}$ of $<20 \%$. Median DoR was longer and the resection rate higher in patients with the greatest DpR; the number of responders was also highest in the two top DpR categories (Table 3b).

\section{PLANET}

Fifty patients were included in the DpR analysis; median DpR was $48 \%$ overall and was similar in the panitumumab plus FOLFOX4 (47\%) and panitumumab plus FOLFIRI (49\%) groups (Abad et al. 2015). In patients with radiologically confirmed response $(n=24)$, median DpR was $67 \%$ overall $(71 \%$ and $64 \%$ in the panitumumab + FOLFOX 4 and panitumumab + FOLFIRI groups, respectively). As patient-level data were not available from PLANET, analyses of factors associated with $\mathrm{DpR}$ were not possible. No data are currently available from PLANET on the impact of DpR on outcome. 
Fig. 4 Waterfall plots showing distribution of depth of response in patients receiving panitumumab plus FOLFOX (blue bars) or comparator treatment (red bars) (a PRIME; b PEAK studies) ( $R A S$ wild-type population)
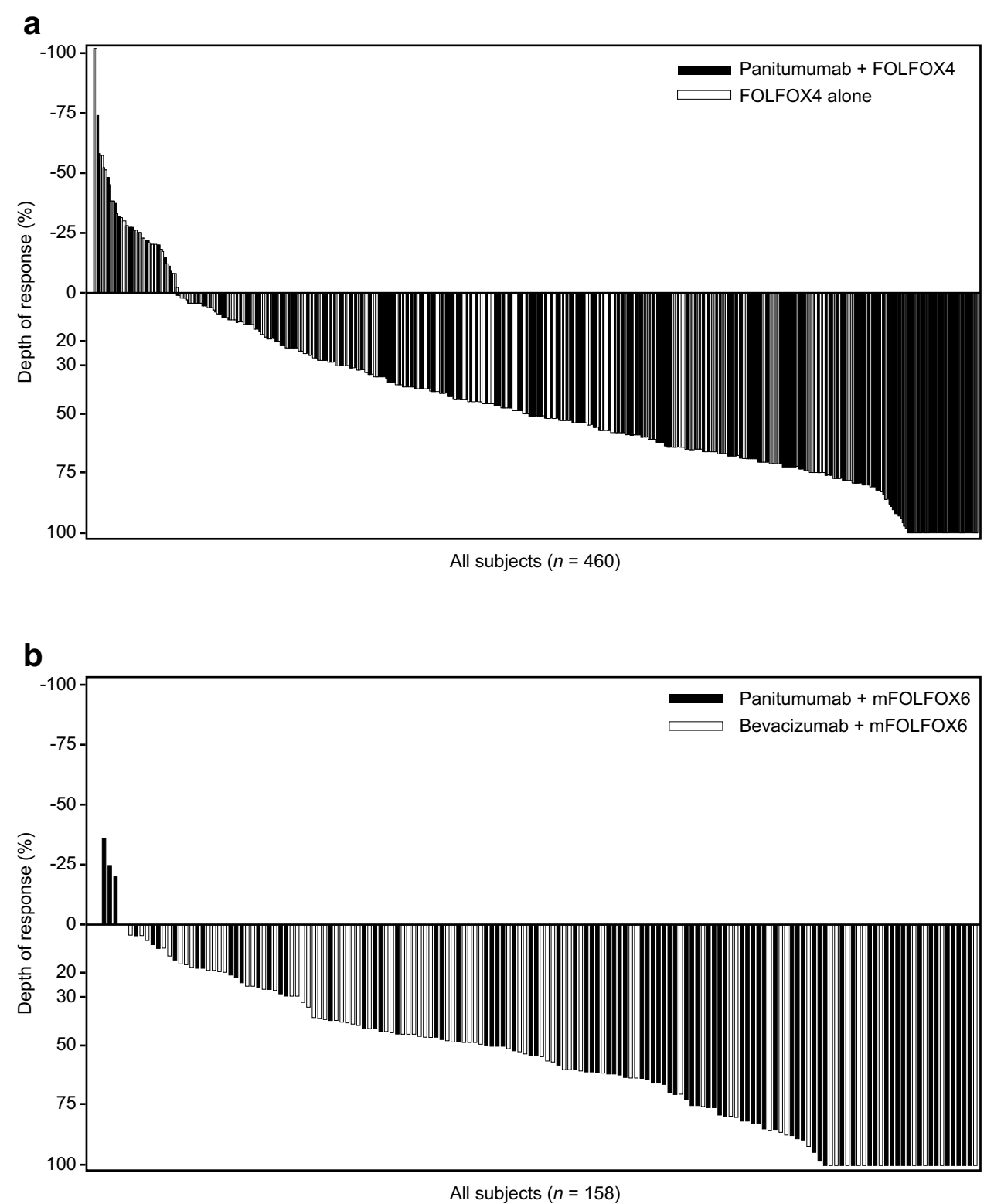

\section{Discussion}

ETS offers the advantage of identifying responders and non-responders after 6-8 weeks of treatment, much earlier than is possible using older measures such as RECIST response. ETS, and also DpR, have previously been associated with long-term outcome in patients with mCRC (Cremolini et al. 2015; Heinemann et al. 2015). Here, we aimed to consolidate the available ETS and DpR data from first-line trials of panitumumab, some of which have only been reported in the form of congress abstracts (Abad et al. 2014, 2015; Rivera et al. 2016; Siena et al. 2016) or in part in full publications (Douillard et al. 2015; Rivera et al. 2017). We have also built on these data by reporting new exploratory analyses of the optimal ETS and
DpR cut-offs to predict improved OS, factors associated with ETS and DpR, and the impact of these endpoints on response and resection, where possible. Taken together, the results of these analyses support an ETS and DpR benefit for panitumumab plus chemotherapy vs. chemotherapy alone or combined with bevacizumab. They are also in line with previous reports of an association between ETS ( $\geq 20 \%$ or $\geq 30 \%$ at week 8 ) and/or DpR during first-line treatment with favourable outcomes in patients with $R A S$ WT mCRC, further supporting the use of these endpoints in the clinic. Furthermore, a recent exploratory analysis of a phase III trial comparing panitumumab plus best supportive care with best supportive care alone, suggested that ETS $\geq 0 \%$ during treatment may also be associated with PFS and OS benefits (Kim et al. 2017). 
Table 3 Efficacy outcomes by depth of response category (a, PRIME; b, PEAK studies) (RAS wild-type population)

\begin{tabular}{|c|c|c|c|c|c|c|}
\hline & \multirow{2}{*}{$\begin{array}{l}\text { DpR continuous } \\
(n=460)\end{array}$} & \multicolumn{5}{|l|}{ DpR category } \\
\hline & & $\begin{array}{l}\text { Group } 1 \\
<0 \% \\
(n=43)\end{array}$ & $\begin{array}{l}\text { Group } 2 \\
0-30 \% \\
(n=83)\end{array}$ & $\begin{array}{l}\text { Group } 3 \\
31-52 \% \\
(n=116)\end{array}$ & $\begin{array}{l}\text { Group } 4 \\
53-70 \% \\
(n=104)\end{array}$ & $\begin{array}{l}\text { Group 5 } \\
71-100 \% \\
(n=114)\end{array}$ \\
\hline PFS events, $n(\%)$ & - & $43(100.0)$ & 79 (95.2) & $107(92.2)$ & $96(92.3)$ & $87(76.3)$ \\
\hline $\begin{array}{l}\text { Median PFS }(95 \% \mathrm{CI}) \text {, } \\
\text { months }\end{array}$ & - & $2.1(1.9,3.3)$ & $5.4(3.9,6.1)$ & $9.3(7.6,10.6)$ & $11.3(9.7,13.7)$ & $16.8(14.6,21.6)$ \\
\hline $\operatorname{HR}(95 \% \mathrm{CI})^{\mathrm{a}}$ & $0.78(0.76,0.81)$ & $9.86(6.7,14.6)$ & $1.70(1.3,2.3)$ & - & $0.79(0.60,1.04)$ & $0.46(0.34,0.61)$ \\
\hline$P$ value & $<0.0001$ & $<0.0001$ & 0.0004 & - & 0.0915 & $<0.0001$ \\
\hline OS events, $n(\%)$ & - & $42(97.7)$ & $79(95.2)$ & $103(88.8)$ & $90(86.5)$ & $66(57.9)$ \\
\hline $\begin{array}{l}\text { Median OS }(95 \% \mathrm{CI}) \text {, } \\
\text { months }\end{array}$ & - & $7.5(5.5,9.4)$ & $12.9(9.2,16.1)$ & $18.9(15.7,21.4)$ & $30.0(23.8,32.5)$ & $48.1(42.5,56.0)$ \\
\hline $\mathrm{HR}(95 \% \mathrm{CI})^{\mathrm{a}}$ & $0.83(0.81,0.85)$ & $2.92(2.03,4.19)$ & $1.48(1.10,1.98)$ & - & $0.63(0.48,0.84)$ & $2.60(0.19,0.36)$ \\
\hline$P$ value & $<0.0001$ & $<0.0001$ & 0.0092 & - & 0.0015 & $<0.0001$ \\
\hline Responders, $n(\%)$ & - & - & - & $72(62.1)$ & $96(92.3)$ & $97(85.1)$ \\
\hline $\begin{array}{l}\text { Median DoR }(95 \% \text { CI }) \text {, } \\
\text { months }\end{array}$ & - & - & - & $7.6(5.5,9.5)$ & $9.4(7.9,10.1)$ & $13.9(11.1,19.3)$ \\
\hline Any resection, $n(\%)$ & - & $0(0.0)$ & $0(0.0)$ & $6(5.2)$ & $6(5.8)$ & $51(44.7)$ \\
\hline \multirow[t]{3}{*}{$\mathrm{R} 0$ resection, $n(\%)$} & - & $0(0.0)$ & $0(0.0)$ & $5(4.3)$ & $1(1.0)$ & $39(34.2)$ \\
\hline & \multirow{2}{*}{$\begin{array}{l}\text { DpR continuous } \\
(n=158)\end{array}$} & \multicolumn{5}{|l|}{ DpR category } \\
\hline & & $\begin{array}{l}\text { Group } 1 \\
<0 \% \\
(n=3)\end{array}$ & $\begin{array}{l}\text { Group } 2 \\
0-30 \% \\
(n=33)\end{array}$ & $\begin{array}{l}\text { Group } 3 \\
31-52 \% \\
(n=41)\end{array}$ & $\begin{array}{l}\text { Group } 4 \\
54-82 \% \\
(n=40)\end{array}$ & $\begin{array}{l}\text { Group 5 } \\
83-100 \% \\
(n=41)\end{array}$ \\
\hline PFS events, $n(\%)$ & - & $3(100.0)$ & $30(90.9)$ & $39(95.1)$ & $39(97.5)$ & $28(68.3)$ \\
\hline $\begin{array}{l}\text { Median PFS (95\% CI), } \\
\text { months }\end{array}$ & - & $3.9(1.8,3.9)$ & $7.6(5.7,11.6)$ & $9.5(7.2,12.6)$ & $13.0(10.7,15.1)$ & $18.8(13.2,24.8)$ \\
\hline $\operatorname{HR}(95 \% \mathrm{CI})^{\mathrm{a}}$ & $0.80(0.75,0.85)$ & $18.98(5.0,72.4)$ & $1.54(1.0,2.5)$ & - & $0.69(0.44,1.08)$ & $0.27(0.16,0.45)$ \\
\hline$P$ value & $<0.0001$ & $<0.0001$ & 0.0781 & - & 0.1007 & $<0.0001$ \\
\hline $\begin{array}{l}\text { OS events, } \\
n(\%)\end{array}$ & - & $2(66.7)$ & $29(87.9)$ & $37(90.2)$ & $29(72.5)$ & $9(22.0)$ \\
\hline $\begin{array}{l}\text { Median OS }(95 \% \mathrm{CI}) \text {, } \\
\text { months }\end{array}$ & - & $15.0(8.9,21.2)$ & $17.3(11.1,21.8)$ & $23.9(16.9,28.9)$ & $36.5(26.0,43.8)$ & $63.0(48.0, \mathrm{NE})$ \\
\hline $\mathrm{HR}(95 \% \mathrm{CI})^{\mathrm{a}}$ & $0.78(0.73,0.83)$ & $2.62(0.62,11.05)$ & $1.26(0.77,2.05)$ & - & $0.49(0.30,0.80)$ & $0.09(0.04,0.19)$ \\
\hline$P$ value & $<0.0001$ & 0.1898 & 0.3543 & - & 0.0046 & $<0.0001$ \\
\hline Responders, $n(\%)$ & - & - & - & $34(82.9)$ & $38(95.0)$ & $33(80.5)$ \\
\hline $\begin{array}{l}\text { Median DoR }(95 \% \text { CI }) \text {, } \\
\text { months }\end{array}$ & - & - & - & $7.9(5.5,9.2)$ & $11.1(8.4,13.5)$ & $17.0(10.3,23.2)$ \\
\hline Any resection, $n(\%)$ & - & $0(0.0)$ & $1(3.0)$ & $0(0.0)$ & $2(5.0)$ & $20(48.8)$ \\
\hline R0 resection, $n(\%)$ & - & $0(0.0)$ & $1(3.03)$ & $0(0.0)$ & $0(0.0)$ & $15(36.6)$ \\
\hline
\end{tabular}

$C I$ confidence interval, $D P R$ depth of response, $H R$ hazard ratio, $N E$ not evaluable, $O S$ overall survival, $P F S$ progression-free survival, $R O$ complete resection

${ }^{a}$ Group HR compared with Group 3, continuous HR estimate is for the HR associated with a $10 \%$ difference in DpR

${ }^{\mathrm{b}}$ Test for trend

Individual study data from two randomised first-line panitumumab trials suggest that patients with $R A S$ WT $\mathrm{mCRC}$ receiving panitumumab have higher rates of ETS than those receiving treatment without panitumumab (ETS $\geq 30 \%$ : PRIME 59\% vs. 38\% (Douillard et al. 2015); PEAK 64\% vs. 45\% (Rivera et al. 2017), respectively). In the new multiple regression analyses, factors associated with improved ETS that were consistent in both the PRIME and PEAK studies were panitumumab treatment, liver-only metastatic disease and WT BRAF status. ETS was associated with improved PFS and OS outcomes in all three first-line panitumumab studies (Abad et al. 2015; Douillard et al. 2015; Rivera et al. 2017) and also in the exploratory study-level meta-analysis (Rivera et al. 


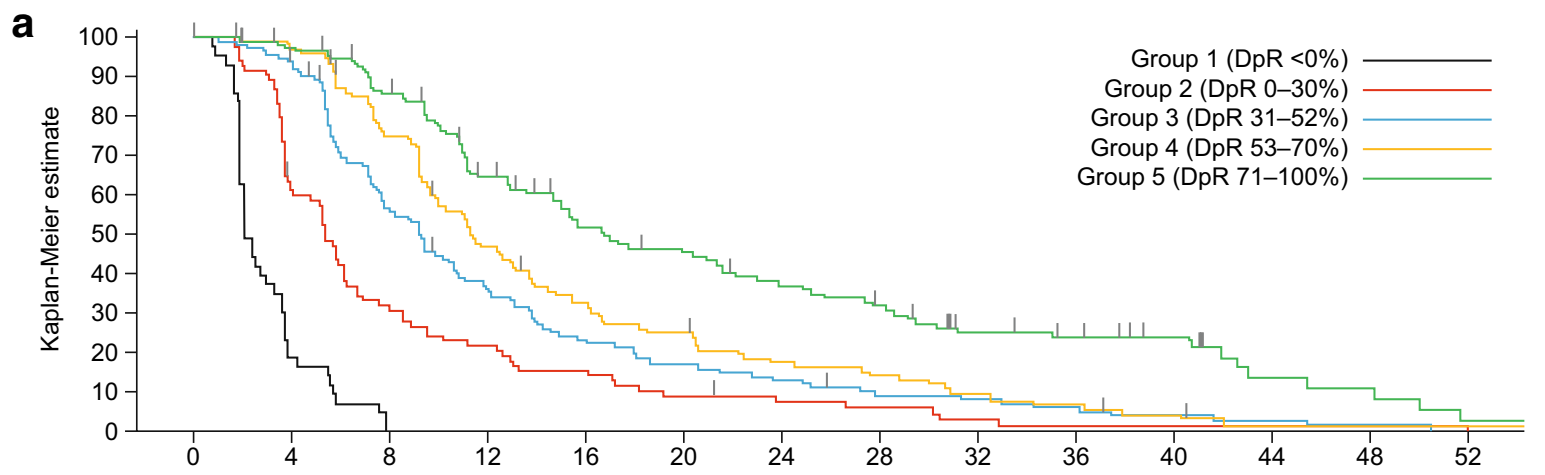

Progression-free survival (months)

Number of subjects at risk

\begin{tabular}{|c|c|c|c|c|c|c|c|c|c|c|c|c|c|}
\hline Group 5 (DpR 71-100\%) & 114 & 110 & 96 & 68 & 51 & 44 & 35 & 29 & 19 & 16 & 11 & 5 & 4 \\
\hline Group 4 (DpR 53-70\%) & 104 & 100 & 75 & 46 & 31 & 24 & 16 & 13 & 9 & 6 & 4 & 1 & 1 \\
\hline Group 3 (DpR 31-52\%) & 116 & 105 & 61 & 39 & 25 & 18 & 14 & 9 & 8 & 6 & 3 & 2 & 1 \\
\hline Group 2 (DpR 0-30\%) & 83 & 48 & 25 & 17 & 12 & 7 & 5 & 4 & 2 & 1 & 1 & 1 & 1 \\
\hline Group 1 (DpR <0\%) & 43 & 8 & 0 & & & & & & & & & & \\
\hline
\end{tabular}

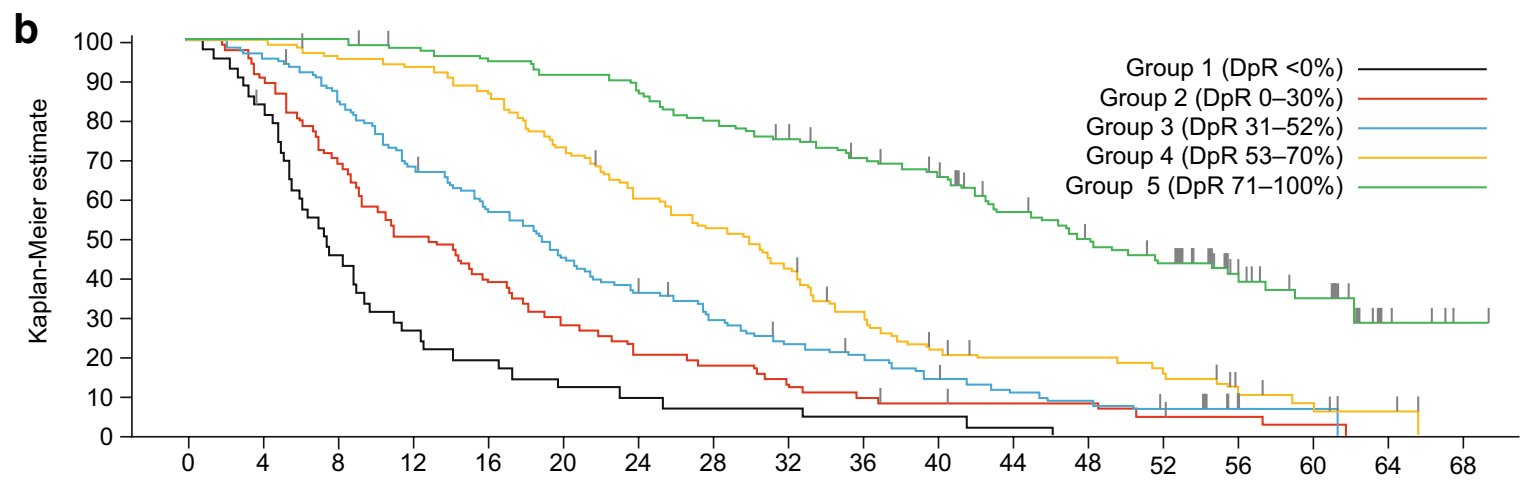

Overall survival (months)

Number of subjects at risk

\begin{tabular}{|c|c|c|c|c|c|c|c|c|c|c|c|c|c|c|c|c|c|}
\hline Group 5 (DpR 71-100\%) & 114 & 114 & 114 & 110 & 107 & 102 & 98 & 89 & 83 & 75 & 68 & 54 & 46 & 39 & 23 & 16 & 5 \\
\hline Group 4 (DpR 53-70\%) & 104 & 104 & 99 & 96 & 90 & 75 & 61 & 53 & 43 & 30 & 20 & 16 & 16 & 13 & 6 & 3 & 2 \\
\hline Group 3 (DpR 31-52\%) & 116 & 112 & 98 & 78 & 65 & 51 & 41 & 32 & 24 & 20 & 14 & 10 & 8 & 5 & 1 & 1 & 0 \\
\hline Group 2 (DpR 0-30\%) & 83 & 75 & 58 & 42 & 33 & 23 & 17 & 15 & 11 & 8 & 6 & 5 & 5 & 3 & 2 & 1 & 0 \\
\hline Group 1 (DpR <0\%) & 43 & 35 & 19 & 11 & 8 & 5 & 3 & 3 & 3 & 2 & 2 & 1 & 0 & & & & \\
\hline
\end{tabular}

Fig. 5 Impact of depth of response (DpR) on survival in the PRIME study (a progression-free survival; b overall survival) (RAS wild-type population) censor indicated by vertical bar

2016). The association of ETS with PFS and OS outcomes were similar irrespective of whether the data were analysed using the $\geq 20 \%$ or $\geq 30 \%$ cut-offs, suggesting that either cut-off can be used. These data support the value of ETS as a predictor for outcomes and are in line with those previously reported in first-line trials of cetuximab and bevacizumab (Modest et al. 2013; Cremolini et al. 2015; Giessen et al. 2013; Heinemann et al. 2015; Stintzing et al. 2016; Tsuji et al. 2016), and a meta-analysis of first-line data for chemotherapy \pm targeted agents (Petrelli et al. 2015). Here we built on previous data for panitumumab by analysing the optimal ETS and DpR cut-offs 


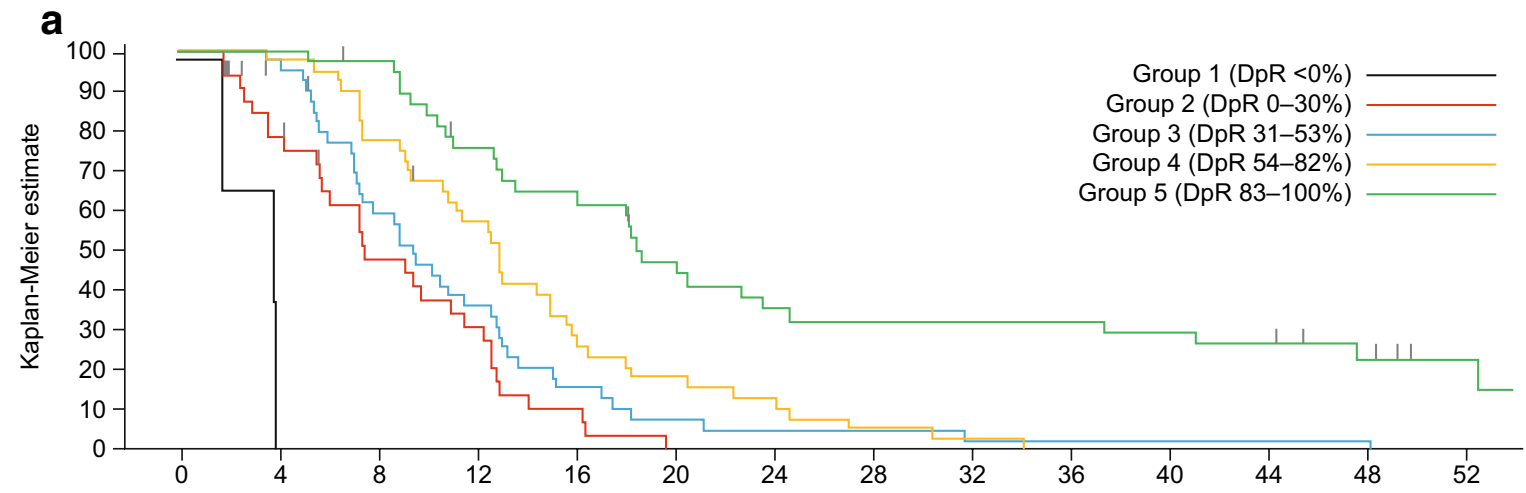

Progression-free survival (months)

Number of subjects at risk

\begin{tabular}{|c|c|c|c|c|c|c|c|c|c|c|c|c|c|}
\hline Group 5 (DpR 83-100\%) & 41 & 38 & 36 & 27 & 23 & 16 & 12 & 11 & 11 & 11 & 10 & 9 & 6 \\
\hline Group 4 (DpR 54-82\%) & 40 & 39 & 31 & 22 & 11 & 7 & 5 & 2 & 1 & 0 & & & \\
\hline Group 3 (DpR 31-53\%) & 41 & 39 & 23 & 14 & 6 & 3 & 2 & 2 & 1 & 1 & 1 & 1 & 1 \\
\hline Group 2 (DpR 0-30\%) & 33 & 25 & 14 & 9 & 3 & 0 & & & & & & & \\
\hline Group 1 (DpR <0\%) & 3 & 0 & & & & & & & & & & & \\
\hline
\end{tabular}

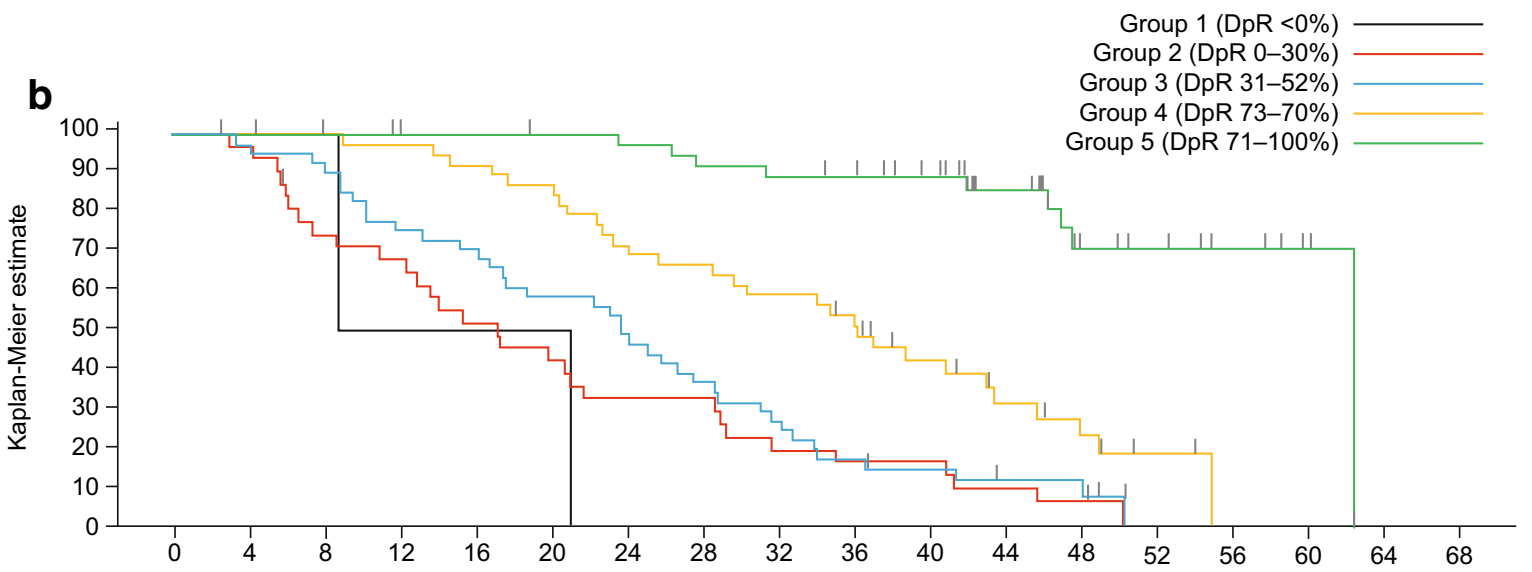

Overall survival (months)

Number of subjects at risk

Group 5 (DpR 83-100\%)

Group 4 (DpR 54-82\%)

Group 3 (DpR 31-53\%)

Group 2 (DpR 0-30\%)

Group $1(\mathrm{DpR}<0 \%)$

$\begin{array}{cccccccccccccccc}41 & 41 & 41 & 40 & 39 & 38 & 37 & 35 & 34 & 33 & 29 & 21 & 14 & 10 & 6 & 4 \\ 40 & 40 & 40 & 38 & 36 & 34 & 28 & 26 & 23 & 20 & 13 & 8 & 6 & 2 & 0 & \\ 41 & 40 & 38 & 31 & 29 & 24 & 20 & 15 & 11 & 7 & 5 & 3 & 3 & 0 & \\ 33 & 31 & 23 & 21 & 16 & 14 & 10 & 10 & 7 & 5 & 5 & 3 & 2 & 0 & \\ 3 & 3 & 2 & 1 & 1 & 1 & 0 & & & & & & & & \end{array}$

Fig. 6 Impact of depth of response (DpR) on survival in the PEAK study (a progression-free survival; b overall survival) (RAS wild-type population) censor indicated by vertical bar

for predicting improved OS. The ETS values reported here were similar in the PRIME and PEAK studies (32 and $34 \%$, respectively), but were higher than the cut-off previously reported in the first-line bevacizumab TRIBE study (17\%) (Cremolini et al. 2015). Although the $\geq 30 \%$ ETS cut-off is the same as that used to define a response in
RECIST, the ETS measure differs in that it reports those achieving $\geq 30 \%$ shrinkage at a specific time point (week 8 here) and does not require that this is confirmed at a subsequent visit. ETS has the benefit that a result is gained more rapidly than for a best response based on RECIST and so can quickly identify early responders to treatment in 
the clinic. Non-responders can also be recognised sooner, thereby permitting an early switch to potentially more effective or better tolerated treatment.

Patients receiving panitumumab in these studies also had greater DpR compared with non-panitumumabcontaining comparator arms in patients with RAS WT mCRC (Douillard et al. 2015; Rivera et al. 2017). In a new exploratory analysis assessing factors associated with $\mathrm{DpR}$, the only factors that were consistently associated with improved DpR across the PRIME and PEAK studies were panitumumab treatment, liver-only metastatic disease and WT BRAF status. ECOG performance status and age were also associated in the PRIME and PEAK studies, respectively. Additional exploratory analyses from PRIME (Siena et al. 2016) and PEAK suggest that deeper responses are associated with longer PFS, OS and also improved DoR and higher resection rates. As might be expected, the vast majority of resections occurred in patients with the highest categories of DpR (71-100\% in PRIME and $83-100 \%$ in PEAK). In line with previous reports, DpR was associated with PFS and OS, irrespective of treatment received (Nozawa et al. 2014; Cremolini et al. 2015; Heinemann et al. 2015; Stintzing et al. 2016; Tsuji et al. 2016). The optimal DpR cut-offs derived here for prediction of improved OS in the PRIME and PEAK studies were 59 and $70 \%$, respectively, which are broadly in line with the cut-off reported in the TRIBE study (62\%) (Cremolini et al. 2015). In PEAK, higher rates of ETS and greater median $\mathrm{DpR}$ were observed for panitumumab plus mFOLFOX6 vs. bevacizumab plus mFOLFOX6 (Rivera et al. 2017). Similar observations have been reported in the first-line FIRE-3 trial comparing cetuximab plus FOLFIRI vs. bevacizumab plus FOLFIRI (Stintzing et al. 2016). Interestingly, recent data from FIRE-3 suggest that ETS may also signal a subgroup of patients with right-sided mCRC who may benefit from treatment with an EGFRi plus chemotherapy (Holch et al. 2017). Taken together, these results suggest a potential benefit for EGFRis vs. bevacizumab for these response-related endpoints and could in part explain the improved OS also seen for these agents (Khattak et al. 2015; Heinemann et al. 2016).

In the clinic, achieving ETS and maximal DpR are likely to be of particular benefit to patients with symptomatic disease and those with potential to convert to resectable status. Consistent with this, in the studies analysed here, resections were mostly reported in patients who had experienced $\geq 20 \%$ or $\geq 30 \%$ ETS and in those with the greatest $\mathrm{DpR}$. Achieving shrinkage early in potentially resectable patients could be important to permit resection as soon as possible, thereby avoiding potential liver toxicities and/or surgical complications due to prolonged treatment. Achieving these endpoints could also provide reassurance of likely treatment benefit and positive long-term survival outcomes.
Strengths of the present analyses include the fact that we included multiple panitumumab studies and a relatively large number of patients that the OS data from these studies are quite mature and that study-level meta-analyses were performed, where possible. We acknowledge there are, however, several limitations of these analyses-they were exploratory and retrospective in nature, there were differences in patient populations between studies, and the number of patients was limited in certain analyses. There is also a lack of clarity regarding the optimum ETS cutoff ( 20 or $30 \%$ ) to use as definitions vary between studies. Furthermore, as we did not have access to patient-level data from all the studies, only a study-level meta-analysis of ETS could be performed and some of the ETS and DpR analyses were not possible for PLANET. There are also other factors unaccounted for in these analyses (e.g. primary tumour location (Yahagi et al. 2016), BRAF mutation status (Clarke and Kopetz 2015), etc.), which are also likely to impact on survival outcomes.

In conclusion, these exploratory analyses suggest that panitumumab plus chemotherapy may offer ETS and DpR benefits over chemotherapy alone or combined with bevacizumab in patients with RAS WT mCRC. Furthermore, ETS ( $\geq 20 \%$ or $\geq 30 \%$ at week 8 ) and DpR during first-line treatment are associated with favourable clinical outcomes.

Acknowledgements The authors wish to acknowledge the patients who participated in the PEAK (NCT00819780), PLANET (NCT00885885) and PRIME (NCT00364013) studies, the study investigators and their staff, and the study team at Amgen. These studies were funded by Amgen Inc. Dawn Batty PhD of Bioscript Medical Ltd, Macclesfield, UK, provided medical writing support, which was funded by Amgen (Europe) GmbH, Zug, Switzerland.

\section{Compliance with ethical standards}

Conflict of interest JT has honoraria, consulting, and/or advisory roles for Amgen, Baxalta, Celgene, Lilly, Merck, Roche, Sanofi, Servier, and Sirtex. FR acted on advisory boards and/or received research funding from Amgen, Bayer, Celgene, Lilly, Merck Serono, Merck Sharp \& Dohme, Roche, Sanofi, and Servier. SS is a member of advisory boards for Amgen, Bayer, Celgene, Lilly, Merck, Merrimack, Novartis, Roche, and Sanofi. MK has a consulting/advisory role for Amgen including participating in steering committees and has received travel, accommodation and expenses from Amgen. MVA has acted on advisory boards and received research funding from Amgen, Merck-Serono, Roche and Sanofi. JG has consulting/advisory roles for Amgen, Bayer, Celgene, Lilly, Merck Serono, Roche, and Sanofi and has received travel, accommodation and expenses from Roche. MG has received research funding and acted in consultancy/advisory roles for Amgen, Bayer, Lilly, Merck and Sanofi. RK is an employee of Amgen Ltd and owns restricted shares in Amgen. GD is an employee of Amgen (Europe) $\mathrm{GmbH}$ and owns restricted shares in Amgen. MP has received research funding from Amgen, Roche and Sirtex, and honoraria from Amgen, Merck Serono, Roche, Sanofi Aventis, Servier, and Sirtex.

Ethical approval All procedures performed in the original studies were in accordance with the ethical standards of the institutional and/ 
or national research committee and with the 1964 Helsinki declaration and its later amendments or comparable ethical standards.

Informed consent Informed consent was obtained for all participants before any study-related procedures were performed. No formal consent was required for these retrospective analyses.

Open Access This article is distributed under the terms of the Creative Commons Attribution 4.0 International License (http://creativecommons.org/licenses/by/4.0/), which permits unrestricted use, distribution, and reproduction in any medium, provided you give appropriate credit to the original author(s) and the source, provide a link to the Creative Commons license, and indicate if changes were made.

\section{References}

Abad A, Massuti B, Grávalos C, Escudero P, Guillén-Ponce C, Manzano JL, Gomez A, Safont MJ, Gallego J, Sastre J, Pericay C, Dueñas R, López-López C, Losa F, Valladares M, González E, Yuste A, Carrato A, Aranda E, On behalf of the Spanish Cooperative Group for the Treatment of Digestive Tumors (TTD) (2014) Phase II trial of panitumumab plus FOLFOX4 or FOLFIRI in subjects with KRAS wild-type colorectal cancer and liver-limited disease: The PLANET study. J Clin Oncol 32(Suppl):3560

Abad A, Massuti B, Grávalos C, Escudero P, Guillén-Ponce C, Manzano JL, Ortiz MJ, Safont MJ, Gallego J, Sastre J, Pericay C, Dueñas R, Rivera F, Losa F, Valladares-Ayerbes M, González E, Robles L, Aranda E, Carrato A, On behalf of the Spanish Cooperative Group for the Treatment of Digestive Tumors (TTD) ( (2015) Early tumour shrinkage (ETS) and depth of response (DpR) with first-line panitumumab (P) plus FOLFOX4 (P-FOLFOX4) or FOLFIRI (P-FOLFIRI) in patients (pts) with wild-type (WT) RAS colorectal cancer (CRC) and liver-limited disease. Eur J Cancer 51(Suppl):S374-S375

Clarke CN, Kopetz ES (2015) BRAF mutant colorectal cancer as a distinct subset of colorectal cancer: clinical characteristics, clinical behavior, and response to targeted therapies. J Gastrointest Oncol 6:660-667

Contal C, O'Quigley J (1999) An application of changepoint methods in studying the effect of age on survival in breast cancer. Comput Stat Data Anal 30:253-270

Cremolini C, Loupakis F, Antoniotti C, Lonardi S, Masi G, Salvatore L, Cortesi E, Tomasello G, Spadi R, Zaniboni A, Tonini G, Barone C, Vitello S, Longarini R, Bonetti A, D’Amico M, Di Donato S, Granetto C, Boni L, Falcone A (2015) Early tumor shrinkage and depth of response predict long-term outcome in metastatic colorectal cancer patients treated with first-line chemotherapy plus bevacizumab: results from phase III TRIBE trial by the Gruppo Oncologico del Nord Ovest. Ann Oncol 26:1188-1194

DerSimonian R, Laird N (1986) Meta-analysis in clinical trials. Control Clin Trials 7:177-188

Douillard JY, Siena S, Cassidy J, Tabernero J, Burkes R, Barugel M, Humblet Y, Bodoky G, Cunningham D, Jassem J, Rivera F, Kocakova I, Ruff P, Blasinska-Morawiec M, Smakal M, Canon JL, Rother M, Oliner KS, Wolf M, Gansert J (2010) Randomized, phase III trial of panitumumab with infusional fluorouracil, leucovorin, and oxaliplatin (FOLFOX4) vs FOLFOX4 alone as firstline treatment in patients with previously untreated metastatic colorectal cancer: the PRIME study. J Clin Oncol 28:4697-4705

Douillard JY, Siena S, Peeters M, Koukakis R, Terwey JH, Tabernero $\mathrm{J}$ (2015) Impact of early tumour shrinkage and resection on outcomes in patients with wild-type RAS metastatic colorectal cancer. Eur J Cancer 51:1231-1242

Eisenhauer EA, Therasse P, Bogaerts J, Schwartz LH, Sargent D, Ford R, Dancey J, Arbuck S, Gwyther S, Mooney M, Rubinstein L, Shankar L, Dodd L, Kaplan R, Lacombe D, Verweij J (2009) New response evaluation criteria in solid tumours: revised RECIST guideline (version 1.1). Eur J Cancer 45:228-247

Folprecht G, Gruenberger T, Bechstein WO, Raab HR, Lordick F, Hartmann JT, Lang H, Frilling A, Stoehlmacher J, Weitz J, Konopke R, Stroszczynski C, Liersch T, Ockert D, Herrmann T, Goekkurt E, Parisi F, Köhne CH (2010) Tumour response and secondary resectability of colorectal liver metastases following neoadjuvant chemotherapy with cetuximab: the CELIM randomised phase 2 trial. Lancet Oncol 11:38-47

Giessen C, Laubender RP, Fischer von Weikersthal L, Schalhorn A, Modest DP, Stintzing S, Haas M, Mansmann UR, Heinemann V (2013) Early tumor shrinkage in metastatic colorectal cancer: retrospective analysis from an irinotecan-based randomized firstline trial. Cancer Sci 104:718-724

Heinemann V, Stintzing S, Modest DP, Giessen-Jung C, Michl M, Mansmann UR (2015) Early tumour shrinkage (ETS) and depth of response $(\mathrm{DpR})$ in the treatment of patients with metastatic colorectal cancer (mCRC). Eur J Cancer 51:1927-1936

Heinemann V, Rivera F, O’Neil BH, Stintzing S, Koukakis R, Terwey JH, Douillard JY (2016) A study-level meta-analysis of efficacy data from head-to-head first-line trials of epidermal growth factor receptor inhibitors vs bevacizumab in patients with RAS wild-type metastatic colorectal cancer. Eur J Cancer 67:11-20

Holch JW, Stintzing S, Held S, Fischer von Weikersthal L, Decker T, Kiani A, Vehling-Kaiser U, Al-Batran SE, Heintges T, Kahl C, Kullmann F, Scheithauer W, Kirchner T, von Einem JC, Modest DP, Heinemann V (2017) Right-sided colorectal cancer (RC): response to first-line chemotherapy in FIRE-3 (AIO KRK-0306) with focus on early tumor shrinkage (ETS) and depth of response (DpR). J Clin Oncol 35(Suppl):3586

Khattak MA, Martin H, Davidson A, Phillips M (2015) Role of firstline anti-epidermal growth factor receptor therapy compared with anti-vascular endothelial growth factor therapy in advanced colorectal cancer: a meta-analysis of randomized clinical trials. Clin Colorectal Cancer 14:81-90

Kim TW, Elme A, Park JH, Udrea AA, Manojlovic NS, Guan X, Jung AS, Vrdoljak E (2017) Early tumor shrinkage (ETS) and depth of response (DpR) in wild-type (WT) RAS tumors from the phase III trial of panitumumab (pmab) plus best supportive care (BSC) vs BSC in chemorefractory metastatic colorectal cancer (mCRC). J Clin Oncol 35(Suppl):3561

Mansmann UR, Sartorius U, Laubender RP, Giessen CA, Esser R, Heinemann V (2013) Deepness of response: a quantitative analysis of its impact on post-progression survival time after first-line treatment in patients with mCRC. J Clin Oncol 30(Suppl 34):427

Modest DP, Laubender RP, Stintzing S, Giessen C, Schulz C, Haas M, Mansmann U, Heinemann V (2013) Early tumor shrinkage in patients with metastatic colorectal cancer receiving first-line treatment with cetuximab combined with either CAPIRI or CAPOX: an analysis of the German AIO KRK 0104 trial. Acta Oncol 52:956-962

Nozawa H, Nishikawa T, Tanaka T, Tanaka J, Kiyomatsu T, Kawai K, Hata K, Kazama S, Yamaguchi H, Ishihara S, Sunami E, Kitayama J, Watanabe T (2014) 'Deepness of response' is associated with overall survival in standard systemic chemotherapy for metastatic colorectal cancer. Chemotherapy 60:360-367

Petrelli F, Pietrantonio F, Cremolini C, Di Bartolomeo M, Coinu A, Lonati V, De Braud F, Barni S (2015) Early tumour shrinkage as a prognostic factor and surrogate end-point in colorectal cancer: a systematic review and pooled-analysis. Eur J Cancer 51:800-807 
Piessevaux H, Buyse M, Schlichting M, Van Cutsem E, Bokemeyer C, Heeger S, Tejpar S (2013) Use of early tumor shrinkage to predict long-term outcome in metastatic colorectal cancer treated with cetuximab. J Clin Oncol 31:3764-3775

Rivera F, Karthaus M, Valladares-Ayerbes M, Gallego J, Koukakis R, Demonty G, Douillard JY (2016) An exploratory study-level meta-analysis assessing the impact of early tumour shrinkage on overall survival in patients with $R A S$ wild-type metastatic colorectal cancer receiving first-line treatment in three randomised panitumumab trials. Ann Oncol 27(Suppl 2):Abstract PD-031

Rivera F, Karthaus M, Hecht JR, Sevilla I, Forget F, Fasola G, Canon JL, Guan X, Demonty G, Schwartzberg LS (2017) Final analysis of the randomised PEAK trial: overall survival and tumour responses during first-line treatment with mFOLFOX6 plus either panitumumab or bevacizumab in patients with metastatic colorectal carcinoma. Int J Colorectal Dis (in press)

Schwartzberg LS, Rivera F, Karthaus M, Fasola G, Canon JL, Hecht JR, Yu H, Oliner KS, Go WY (2014) PEAK: a randomized, multicenter phase II study of panitumumab plus modified fluorouracil, leucovorin, and oxaliplatin (mFOLFOX6) or bevacizumab plus mFOLFOX6 in patients with previously untreated, unresectable, wild-type KRAS exon 2 metastatic colorectal cancer. J Clin Oncol 32:2240-2247

Siena S, Rivera F, Douillard JY, Taieb J, Koukakis R, Demonty G, Peeters M (2016) Impact of depth of response (DpR) on survival in patients (pts) with RAS wild-type (WT) metastatic colorectal cancer (mCRC) receiving first-line panitumumab+FOLFOX4 vs FOLFOX4. Ann Oncol 27(Suppl 6):485P
Stintzing S, Modest DP, Rossius L, Lerch MM, von Weikersthal LF, Decker T, Kiani A, Vehling-Kaiser U, Al-Batran SE, Heintges T, Lerchenmuller C, Kahl C, Seipelt G, Kullmann F, Stauch M, Scheithauer W, Held S, Giessen-Jung C, Moehler M, Jagenburg A, Kirchner T, Jung A, Heinemann V (2016) FOLFIRI plus cetuximab vs FOLFIRI plus bevacizumab for metastatic colorectal cancer (FIRE-3): a post hoc analysis of tumour dynamics in the final RAS wild-type subgroup of this randomised open-label phase 3 trial. Lancet Oncol 17:1426-1434

Therasse P, Arbuck SG, Eisenhauer EA, Wanders J, Kaplan RS, Rubinstein L, Verweij J, Van Glabbeke M, van Oosterom AT, Christian MC, Gwyther SG (2000) New guidelines to evaluate the response to treatment in solid tumors. European Organization for Research and Treatment of Cancer, National Cancer Institute of the United States, National Cancer Institute of Canada. J Natl Cancer Inst 92:205-216

Tsuji A, Sunakawa Y, Ichikawa W, Nakamura M, Kochi M, Denda T, Yamaguchi T, Shimada K, Takagane A, Tani S, Kotaka M, Kuramochi H, Furushima K, Koike J, Yonemura Y, Takeuchi M, Fujii M, Nakajima T (2016) Early tumor shrinkage and depth of response as predictors of favorable treatment outcomes in patients with metastatic colorectal cancer treated with FOLFOX plus cetuximab (JACCRO CC-05). Target Oncol 11:799-806

Yahagi M, Okabayashi K, Hasegawa H, Tsuruta M, Kitagawa Y (2016) The worse prognosis of right-sided compared with left-sided colon cancers: a systematic review and meta-analysis. J Gastrointest Surg 20:648-655 